\section{$\underset{\substack{\text { hommes } \\ \text { \& migrations }}}{ }$}

Hommes \& migrations

Revue française de référence sur les dynamiques

migratoires

$1301 \mid 2013$

Migrations et mondes ruraux

\title{
Rachid Santaki, Des chiffres et des litres
}

Paris, Moisson rouge, 2012, 256 pages, 16,50€

\section{Mustapha Harzoune}

\section{Q OpenEdition \\ 1 Journals}

\section{Édition électronique}

URL : http://journals.openedition.org/hommesmigrations/1963

DOI : 10.4000/hommesmigrations.1963

ISSN : 2262-3353

\section{Éditeur}

Musée national de l'histoire de l'immigration

\section{Édition imprimée}

Date de publication : 1 janvier 2013

Pagination : 211-212

ISBN : 978-2-919040-21-6

ISSN : 1142-852X

Référence électronique

Mustapha Harzoune, «Rachid Santaki, Des chiffres et des litres », Hommes \& migrations [En ligne],

1301 | 2013, mis en ligne le 29 mai 2013, consulté le 22 septembre 2020. URL : http://

journals.openedition.org/hommesmigrations/1963 ; DOI : https://doi.org/10.4000/

hommesmigrations.1963

Ce document a été généré automatiquement le 22 septembre 2020.

Tous droits réservés 


\title{
Rachid Santaki, Des chiffres et des litres
}

Paris, Moisson rouge, 2012, 256 pages, $16,50 €$

\author{
Mustapha Harzoune
}

\section{RÉFÉRENCE}

Rachid Santaki, Des chiffres et des litres, Paris, Moisson rouge, 2012, 256 pages, 16,50€.

1 Avec Des chiffres et des litres, Rachid Santaki signe un roman qui s'inscrit dans la pure tradition du néo-polar. Nous sommes en 1998, la Coupe du monde de football mobilise l'attention du pays. Hachim, un jeune de Saint-Denis intelligent et sensible, doué pour les études souhaite faire carrière dans le journalisme mais s'embarque dans une galère qui n'est pas faite pour lui : le deal de shit. Il faut savoir pourtant rester à sa place, ne pas jouer les gros durs quand on a une "gueule de premier de la classe"! L'appât de l'argent facile, l'admiration qu'il porte à Houssine, son mentor et protecteur, en décideront autrement. Ce dernier, "leader du deal" à Saint-Denis, vient de perdre Jérôme, son associé et ami. Son corps, couvert des stigmates des tortures subies, gît au milieu d'une décharge. Le brutal et violent inspecteur Neterli, surnommé "Hunter", arrive le premier sur les lieux. Mais ce sera Perrin, alias "Papy", inspecteur alcoolique et proche de la retraite, qui enquêtera. Papy, au motif d'une vague dette et d'un devoir moral contracté auprès de son père, protège Houssine. Papy picole au bar d'Omar, l'oncle d'Houssine, histoire de noyer sa culpabilité de refouler ce que ses petits camarades de la police firent un certain 17 octobre 1961.

2 C'est sur cette toile de fond qui croise les trajectoires individuelles et générationnelles, les conflits d'intérêts, la guéguerre des gangs et des polices, l'histoire de l'immigration algérienne, que Santaki brosse, avec une redoutable efficacité, l'univers, pour le coup réellement impitoyable, d'une cité parisienne. Au cœur de ce tableau, il y a la description méticuleuse du trafic de drogue, l'organigramme de la revente au détail, le cursus du bitume et de la "bicrave", les luttes d'influence entre caïds, les flics ripoux, la 
prison, les bandes qui se jaugent dans le quartier des Halles ou de La Défense... Cela est fait sans pathos, sans esbroufe, sans aucune volonté de céder à un exotisme putassier propre à exciter les fantasmes du plus grand nombre. C'est une livraison brut de décoffrage que fait ici l'auteur et c'est ce qui constitue le sel de ce livre. Le lecteur se trouve plongé dans un ordinaire que la plupart ignorent sûrement, un horizon de barres et de tours où règne la loi du plus fort, la codification de relations où la violence - la capacité à l'exercer ou à l'éviter - imprègne tous les rapports. Ici, "avouer son amour pour quelqu'un" représente un "tabou", une "faiblesse", un "handicap". Il faut nourrir sa violence de l'indispensable "seum" et être "sans pitié avec les plus faibles", au risque de devoir le payer cash. La logique suicidaire, destructrice de la violence, son impasse aussi, s'étale par la seule description de l'absurdité d'un quotidien dominé par la peur, l'agression, l'évitement, des codes durs, inhumains, qui obligent à plier ou à se casser ! Santaki, sans démonstration moralisante ou sociologisante, dit beaucoup sur ces banlieues en particulier et sur la société en général. Les Beurs, les Blacks et autres relégués de l'urbain dealent, mais le système vit aussi de ses proprets consommateurs : lycéens ou cadres supérieurs et même policiers. C'est de l'autre côté du périphérique que les trafics en tout genre (drogues ou combats de chiens) trouvent leur clientèle : dans les beaux quartiers et les demeures bourgeoises où l'accent des cités est si “ charmant". Au détour d'un paragraphe, Rachid Santaki invite à réfléchir aux conséquences des politiques dites de "sécurité" qui auraient favorisé les "dérapages" policiers, comment la justification des résultats, la logique du chiffre-roi, peut conduire à bien des dérives et autant de manquements aux droits et aux respects des personnes.

4 Voilà pour l'ombre qui gagne et menace les cités, cette ombre qui court entre des bâtiments fatigués, intimide dans les halls d'immeubles, souille les intérieurs, celui des familles, comme celle de Hachim, laissant une mère éplorée, un père déshonoré et une sœur révoltée. Il n'y a rien de valorisant dans tout cela et rien à valoriser. Qu'on se le dise et qu'on fasse vite et bien circuler le livre (et son message) chez les plus jeunes.

Mais il y aussi, chez Santaki, des raisons d'espérer. Cela sans doute traduit l'énergie polymorphe d'une jeunesse mal-aimée et reléguée. Saint-Denis "bâille une mauvaise haleine, s'étire et se lève. Je l'aime pas pour ses cités, mais pour son âme, ce qu'elle fait de nous, des débrouillards", dit Hachim. Des "débrouillards" qui réussissent à éviter les écueils, s'investissent dans le sport (ici la boxe thaï) ou la création artistique, la poésie version rap, les tags et la musique où, au cœur d'une riche bande-son, émerge le groupe NTM. Cette culture urbaine, portée par une jeunesse métissée qui invente de nouvelles formes d'expression, est, à l'origine, une culture de contestation, une remise en question de l'ordre établi. Mais tout cela aurait été récupéré : "Le mouvement, émergé du bitume grâce à sa rage, s'éteint petit à petit."

6 Ce qui frappe d'entrée à la lecture de ce polar, c'est bien sûr la langue utilisée par l'auteur: mélange de vocabulaires de "téci", de métissages linguistiques qui empruntent aux langues de l'immigration où domine l'arabe. Pas sûr que le lecteur étranger à ce volapük retrouve ses petits entre les "achipe-achopé", "sclague", "teumteum", "heb's" et autres "gueush". Un lexique en fin de volume aurait servi le vulgum pecus. Reconnaissons que Santaki n'en fait pas un usage systématique, une sorte de tic littéraire propre à alpaguer le curieux. Comme le tigre qui n'a pas à affirmer sa tigritude, il sait de quoi il parle et n'en fait pas trop. Il y aurait peut-être une tendance discutable, celle qui consisterait, par souci de reconnaissance, à (sur)valoriser cette culture urbaine née aux confluences de la mondialisation, des migrations et de la 
relégation et à l'opposer à la "culture traditionnelle", la "culture Joconde". Comme si le "ou" devait prendre le pas sur le "et". Comme si l'urgence n'était pas d'harmoniser le divers plutôt que de le fondre dans le grand tout de nouveaux mythes unificateurs et exclusifs. Ce n'est d'ailleurs pas ce que traduisent les doutes et les ambitions de Hachim, les reproches de sa sœur, les conseils d'une enseignante ou ceux de la savoureuse mamie Strange. 